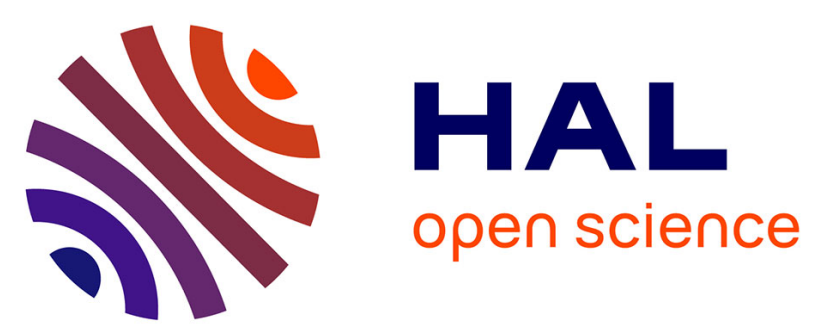

\title{
INFLUENCE OF IMPURITIES AND DISLOCATIONS ON ULTRASONIC ATTENUATION IN COPPER AND DILUTE COPPER ALLOYS AT LOW TEMPERATURES
}

\author{
P. Schrey, J. Schulz, H. Schmidt, D. Lenz
}

\section{To cite this version:}

P. Schrey, J. Schulz, H. Schmidt, D. Lenz. INFLUENCE OF IMPURITIES AND DISLOCATIONS ON ULTRASONIC ATTENUATION IN COPPER AND DILUTE COPPER ALLOYS AT LOW TEMPERATURES. Journal de Physique Colloques, 1981, 42 (C5), pp.C5-671-C5-676. 10.1051/jphyscol:19815103 . jpa-00220971

HAL Id: jpa-00220971 https://hal.science/jpa-00220971

Submitted on 1 Jan 1981

HAL is a multi-disciplinary open access archive for the deposit and dissemination of scientific research documents, whether they are published or not. The documents may come from teaching and research institutions in France or abroad, or from public or private research centers.
L'archive ouverte pluridisciplinaire HAL, est destinée au dépôt et à la diffusion de documents scientifiques de niveau recherche, publiés ou non, émanant des établissements d'enseignement et de recherche français ou étrangers, des laboratoires publics ou privés. 
JOURNAL DE PHYSIQUE

INFLUENCE OF IMPURITIES AND DISLOCATIONS ON ULTRASONIC ATTENUATION IN COPPER AND DILUTE COPPER ALLOYS AT LOW TEMPERATURES

P. Schrey, J. Schulz, H. Schmidt and D. Lenz

Institut für Allgemeine Metallkunde und Metallphysik der RWTH Aachen und Sonderforschungsbereich 125, Aachen - Jülich - Köln, F.R.G.

Abstract. - We have measured the phonon-electron attenuation $\alpha_{\mathrm{PE}}$ $(10<f<200 \mathrm{MHz}$, long. wave in $\langle 111\rangle)$ in $\mathrm{Cu}$ single crystals of widely different purity $(20<$ RRR<20.000) after suppression of dislocation damping by $\gamma$-irradiation. The $a_{\mathrm{PE}}$-data are in agreement with Pippard's theory. The measurements on crystals doped with paramagnetic impurities ( $\mathrm{Fe}, \mathrm{Mn})$ show an "ultrasonic Kondo-effect".

1. Introduction.- At $T<100 \mathrm{~K}$ the ultrasonic attenuation (UA) in pure $\mathrm{Cu}$ (impurity content typically $<10^{2} \mathrm{ppm}$ ) is determined by dislocations (dislocation resonance attenuation $\alpha_{G L}$ ) and electrons (phonon-electron attenuation $\alpha_{\mathrm{PE}} / 1 / 1$. Both effects are superimposed on a comparatively small background attenuation $\alpha_{B}$ (being mainly caused by the thermoelastic effect, sample- and sound field geometry /2/). Fig.1 (upper curve) shows as an example the attenuation of high purity $\mathrm{Cu}(\mathrm{RRR} \sim 1000$, sandwich buffer crystal /3/ to avoid quartz sample deformation $/ 4 / 1$ which strongly increases below $100 \mathrm{~K}$ due to $\alpha_{P E}$. (The sample was slightly $\gamma$-irradiated $\left(\emptyset_{Y}=10^{2} \mu \mathrm{Ah}\right)$ to demonstrate the advantages of the buffer technique). However, by a heavy $\mathrm{Y}$-irradiation which causes strong pinning of the mobile dislocation loops the dislocation attenuation $\alpha_{\mathrm{GL}}$ can be completely suppressed and the $\left(\alpha_{P E}+\alpha_{B}\right)$-contributions remain (lower curve). Since $a_{B}$ is only slightly temperature dependent

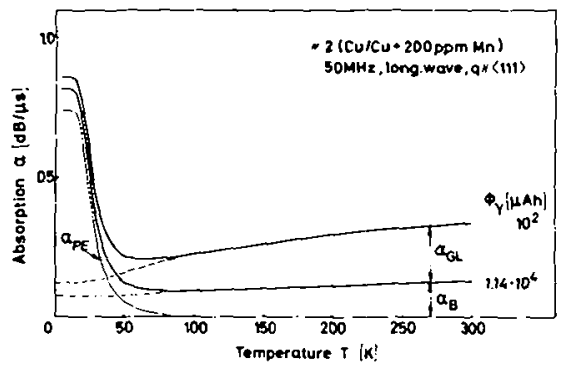

FIG 1

Temperature dependence of dislocation attenuation $\alpha_{\mathrm{GL}}$, background $\alpha_{B}$ and phonon-electron attenuation $\alpha_{P E}$

between 300 and $100 \mathrm{~K}$ the $\alpha(\mathrm{T})$-behaviour after irradiation can be extrapolated to $4.2 \mathrm{~K}$ (dashed dotted curve) in order to separate $\alpha_{\mathrm{PE}}$. Subtraction of $\alpha_{P E}+\alpha_{B}$ finally yields the wanted dislocation attenuation $\alpha_{G L}$ (dashed curve in fig.1).

The present paper reports on $\alpha_{\mathrm{PE}}$ measurements on a wide variety of Cu crystals used for studies of dislocation damping effects. It compares measured $\alpha_{P E}$ with theoretical predictions by using residual resistivity 
ratios $R R R$ measured on the ultrasonic samples. The resulting Pippard factor /5/ then allows calculation of $\alpha_{P E}(T)$ and thus evaluation of $\alpha_{G L}$ from the $a(T)$ measurement and knowledge of RRR without resort to irradiation (i.e. the second $\alpha(T)$-run on the irradiated sample is not needed).

2. Experiment. - We measured longitudinal UA $(10<f<200 \mathrm{MHz})$ in $\langle 111\rangle-$ oriented Cu single crystals between 4.2 and $300 \mathrm{~K}$. Sample preparation is described elsewhere $/ 9 /$. The residual resistivity ratios of the individual samples $(20<R R R<20.000)$ were measured by the eddy current technique $16 /$. The $\gamma$-irradiation was produced by a Van de Graaff electron generator in an Au-target (Frenkel defect (FD) production rate $5.5 \times 10^{9} \mathrm{FD} / \mathrm{cm}^{2} \mathrm{~s}$ /9/. The total irradiation induced defect concentration needed for complete dislocation pinning is $<10^{-3} \mathrm{ppm}$. This low concentration does not influence the RRR and thus $\alpha_{\mathrm{PE}}$ to any measurable extend.

3. Theory of phonon-electron absorption.- According to Pippard (free electron gas assumed $/ 5 / /$ the attenuation $\alpha_{P E}$ of longitudinal sound in a metal is determined by $a=q \cdot l$ with $q=|\vec{q}(111)|=2 \pi f / v_{L}$ the wave number, $\ell$ the mean free path length of the electrons and $v_{L}$ the sound velocity $\left(5.16 \cdot 10^{5} \mathrm{~cm} / \mathrm{s}\right)$

$$
a_{P E}=A_{F E} f \frac{6}{\pi}\left\{\frac{a}{3}\left(\frac{\arctan a}{a-\operatorname{arc} \tan a}\right)-\frac{1}{a}\right\}
$$

$A_{F E}=\pi^{2} \mathrm{NmV}_{F} / 3 \rho_{D} v_{L}^{2}$ with $\mathrm{N}=$ electron concentration, $m$ = electron mass, $v_{F}=$ Fermi-velocity, $\rho_{D}=$ density of $\mathrm{Cu}$. For comparison with experimental results the limits of equ. (1) are useful

$$
\begin{array}{ll}
\mathrm{q} \ell>1 \text { ("pure limit"): } & \alpha_{\mathrm{PE}} / A_{F E} \cdot \mathrm{f}=1 \\
\mathrm{q} \ell=1 \text { ("impure Iimit"): } & \alpha_{\mathrm{PE}} / A_{\mathrm{FE}} \cdot \mathrm{f}=0.5 \mathrm{ql}
\end{array}
$$

The "impure limit" refers to doped crystals (having small \& (i.e. low RRR or high $T$ ) or to measurements at low f). The "pure limit" refers to high purity crystals at lowest $\mathrm{T}$ measured at high frequencies.

4. Results and discussion.- Fig. 2 shows $\alpha_{\mathrm{PE}}(\mathrm{T})$-curves for samples of different purity levels (e.g. RRR $=20.000$ refers to $<0.1$ at ppm total impurity (Fe)). The strong $\alpha_{P E}$ increase between 60 and $20 \mathrm{~K}$ is due to increasing $\ell$. The maximum $\hat{\alpha}_{P E}$ measured at $4.2 \mathrm{~K}$ is determined by $\ell_{0}$ the residual $\ell$ for the "impure" case $(q \ell<1, e . g$. samples $4,6,7)$ where $\hat{\alpha}_{P E ~}$ " $\ell_{0} \sim \mathrm{RRR}$. In the "pure limit" ( $\left(\mathrm{l} l>>1\right.$, sample 1) $\alpha_{\mathrm{PE}}=\mathrm{A}_{\mathrm{FE}} \mathrm{f}$, i.e. the maximum attenuation is given by the Pippard factor $A_{F E}$ (equ. (2)). For comparison of magnitude the dashed curve in fig. 2 shows the dislocation attenuation $\alpha_{\mathrm{GL}}$ measured on sample 2: at $\mathrm{T}>50 \mathrm{~K} \alpha_{\mathrm{PE}}<<\alpha_{\mathrm{GL}}$; however, at $T<10 \mathrm{~K}$ we find $\alpha_{\mathrm{PE}^{-10}} \alpha_{\mathrm{GL}}$. This shows that the knowledge of $\alpha_{\mathrm{PE}}$ is of fundamental importance for the evaluation of dislocation damping at these low $\mathrm{T}$. 


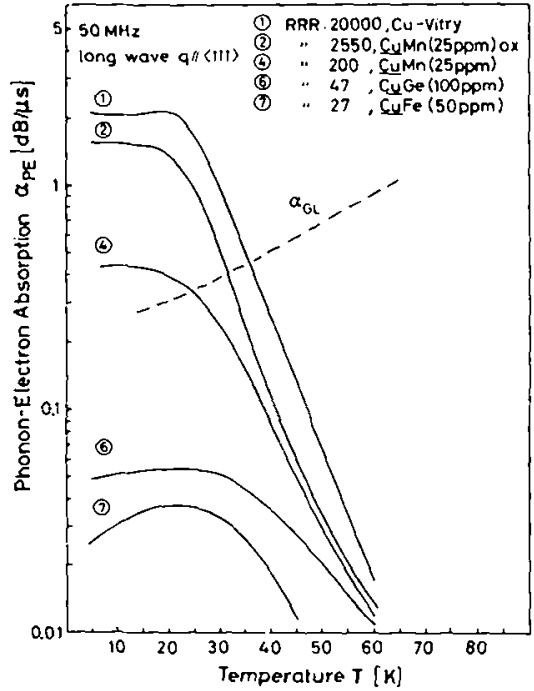

FIG 2 Temperature dependence of $\alpha_{P E}$

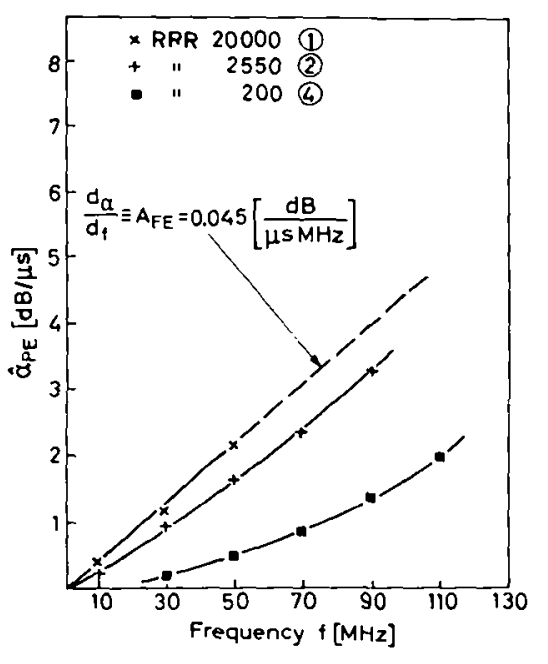

FIG 3 Frequency dependence of $\alpha_{\mathrm{PE}}$

Fig. 3 shows $\alpha_{\mathrm{PE}}(f)$ for three samples of widely different RRR. Whereas the impure samples exhibit curved $\alpha_{P E}$ behaviour (equ. (3)) the highest purity sample 1 shows a linear $\alpha_{P E}(f)$-dependence (equ. (2)). From its slope we obtain the Pippard factor $\mathrm{A}_{\mathrm{FE}}=0.045 \pm 0.005$.

Fig. 4 shows the $T$-dependence of the electronic mean free path $\ell(T)$ derived with help of equ. (3) and $A_{\mathrm{FE}}=0.045$ (left scale). It can be seen that for the low sample purities shown the $\alpha_{\mathrm{PE}} \sim \mathrm{f}^{2}$ dependence is fulfilled within experimental accuracy (right scale). The data can be compared with eIDEAL (T) the "ideal" (lattice-) mean free path length. As to be expected the measured $\ell(T)$ (i.e. $\alpha_{P E}(T)$ ) is determined by $\ell_{\text {IDEAL }}$ at $T>50 \mathrm{~K}$ whereas it becomes impurity controlled at lower $\mathrm{T}$. For $\mathrm{T} \rightarrow 4.2 \mathrm{~K}$ individual $\ell_{0}$ values are measured which scale with the samples $R R R$ values ( $\ell_{0} \sim R R R$ ).

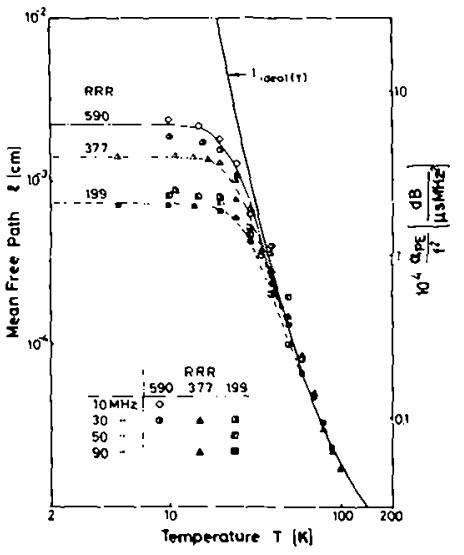

FIG 4

$T$-dependence of electron mean free path length $\ell$ compared with $\ell_{\text {Ideal }}$ 
Fig.5 depicting $\alpha_{P E}(f)$ for the same samples as in fig. 4 shows more directly the $a_{P E} \sim f^{2}$ behaviour (which is seen to break down for the purer sample at hiqhest f). Since $\alpha_{P E} \sim \ell$ (equ. (3)) the slope 2-lines scale with RRR. The dashed line of slope 1 depicts the upper limit of applicability of equ. (3) defined by $\alpha_{P E} / f=0.02$ (see below). From this limiting condition we obtain the experimentally more useful form $\mathrm{E}_{L \mathrm{IM}}{ }^{[\mathrm{MHz}]=}$ $2 \cdot 10^{4} / \mathrm{RRR}$ which limits the $\left(\alpha_{P E} \sim 2\right)-$ range to frequencies $f \leqq f_{L I M}$. For experiments outside this range ( $f>f_{L I M}$ or $\mathrm{RRR}>2 \cdot 10^{4} / 5 \mathrm{MHz}=4.000, \mathrm{f}=5 \mathrm{MHz}$ being the lowest $f$ for the present pulse echo technique) instead of equ. (3) the complete pippard formula (equ. (1)) must be used for calculation of $a_{P E}$.

Fig. 6 shows our $a_{P E} / f$ data (left

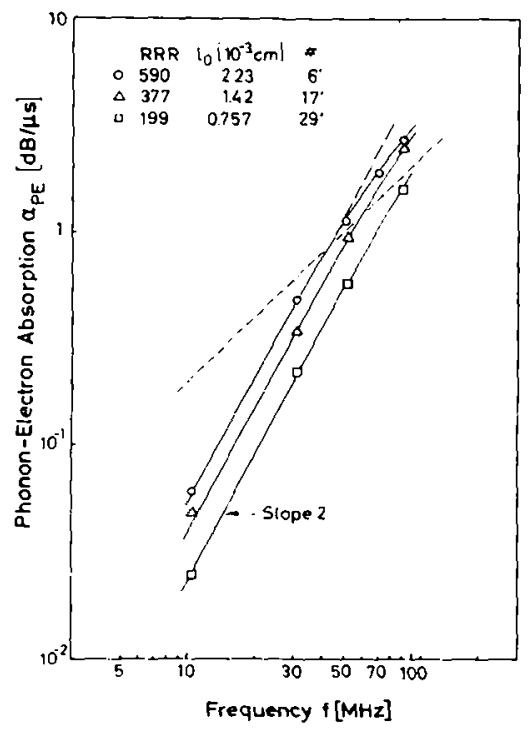

FIG 5

$\alpha_{P E}(f)$ in the $q \cdot \ell<1$ limit defined by $\alpha_{P E} \leq 0.02 \mathrm{f}$ (dashed line) scale) fitted to the theoretical $\alpha_{P E} / A_{F E} \cdot f$ behaviour (equ. (1), right scale). The fit yields $A_{F E}=0.045$ the same value as already derived from the data in the pure limit (dashed line). Pippards equation (1) describes the present data over almost three decades in q $l$ within narrow limits $(10 \%)$. Thus it can be used for calculation of the $\alpha_{P E}$ contribution and separation of the wanted dislocation resonance damping. Up to $a_{P E} / f=0.02$ (i.e. $\left.q l<0.9\right)$ the "impure Iimit" equ. (3) can be used with sufficient accuracy.

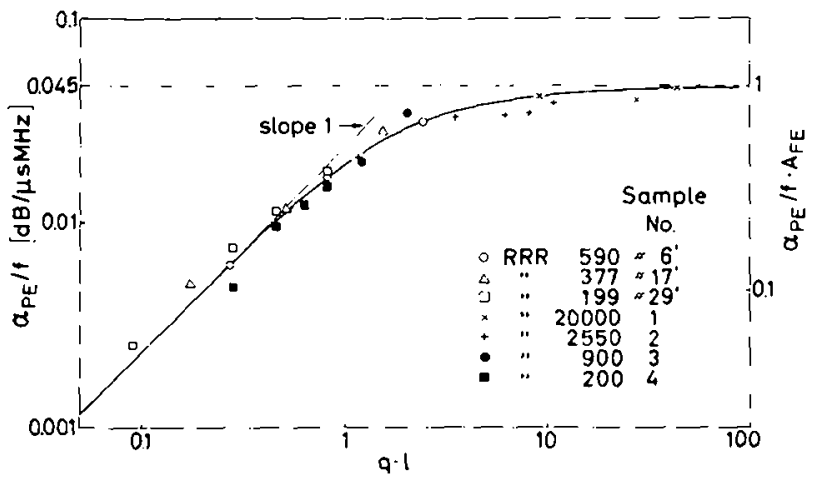

FIG 6 Present $\alpha_{P E}$ data fitted to Pippard equation (equ. (1)) to obtain Pippard factor $A_{\mathrm{FE}}(\leq 0.045)$. 
5. Ultrasonic Kondo-Effect.- our results on crystals doped with paramagnetic impurities ( $\mathrm{Fe}, \mathrm{Mn}$ ) exhibit on "anomaious" $\alpha_{P E}(T)$ dependence (attenuation maximum) at $T$ < 30K (C.f. fig.1, sample 7). Fig.7 shows this for a cu+50ppmFe and a $\mathrm{Cu}+60$ ppmin crystal. We plot the inverse attenuation vs $T$ since according to equ. (3) $f^{2} / \alpha_{\mathrm{PE}} \sim 1 / 2$ is directly proportional to the electrical resistivity $(\rho \sim 1 / l)$. Both results in $\mathrm{fig.7}$ are in accordance with measured $\rho(T)$-curves /7,8/ on dilute CuFe, CuMn which show kondo behaviour. Table 1 (comparing our results with the resistivity-data) shows close agreement between the observed temperature $\mathrm{T}_{\mathrm{KMIN}}$ (Kondo-minimum temperature) and Kondo-slope $\mathrm{SL}_{\mathrm{K}}=[1 / \mathrm{x}(4.2)] \cdot d \mathrm{x} / \mathrm{d} \log \mathrm{T}$ with $\mathrm{x}=\Delta \rho(T) / \mathrm{c}$ $(c=$ impurity concentration) for the electrical resistivity data and $x=f^{2} / \alpha_{P E}(T)$ for the present ultrasonic attenuation data.

TAB. 1

\begin{tabular}{|c|c|c|c|}
\hline \multicolumn{2}{|c|}{} & $\begin{array}{l}\text { Ultrasonic } \\
\text { Attenuation }\end{array}$ & $\begin{array}{c}\text { Electrical } \\
\text { Resistivity }\end{array}$ \\
\hline \multirow{2}{*}{ CuFe } & $\mathrm{T}_{\mathrm{KMIN}}[\mathrm{K}]$ & 22 & $21 / 7 /$ \\
\cline { 2 - 4 } & $\mathrm{SI}_{\mathrm{K}}$ & 0.149 & $0.153 / 7 /$ \\
\hline \multirow{2}{*}{ CuMn } & $\mathrm{T}_{\mathrm{KMIN}}[\mathrm{K}]$ & 17 & $16.2 / 8 /$ \\
\cline { 2 - 4 } & $\mathrm{SI}_{\mathrm{K}}$ & 0.176 & $0.178 / 8 /$ \\
\hline
\end{tabular}

The close agreement between $\mathrm{T}_{\mathrm{K}}$ and $\mathrm{SL}_{\mathrm{K}}$ (measured by attenuation and resistivity) indicates that the same phenomenon is observed. To our knowledge this is the first ultrasonic measurement of Kondo scattering. 


\section{References}

/1/ J.A. Rayne: Proc. 5 $5^{\text {th }}$ ICIFUA, Vol. I, p.13, Springer Berlin 1975

/2/ R. Truell, C. Ellbaum, B.B.Chick: "Ultrasonic Methods in Solid State Physics", Academic Press, New York 1969

/3/ D. Lenz, H. Schmiat: to be published in "zeitschrift fúr Physik B" 41, 1981

/4/ J. Schulz, D. Lenz: this volume

/5/ A.B. Pippard; Phil. Mag. 46, 1104 (1955)

/6/ P. Bean, R.W. De Blois, L.S. Nesbitt: J. Appl. Phys. 30, 1976 (1959)

/7/ G. Holfelder: Dissertation RWTH Aachen (1977)

/8/ P. Monod: Phys. Rev. Lett. 19, 1113 (1967)

19/ P. Winterhager, K. Lïcke: J. Appl. Phys. 44, 4855 (1973) 